\title{
CONTEMPLATING COMPETENCY-BASED EDUCATION AT THOMAS EDISON STATE UNIVERSITY
}

\section{Steve Phillips}

Center for the Assessment of Learning, Thomas Edison State University, Trenton, NJ; steve.c.phillips87@gmail.com

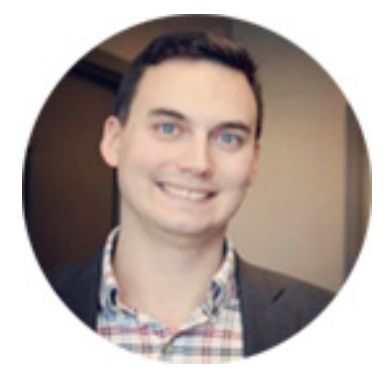

\begin{abstract}
This paper provides an institutional perspective of a single competency-based institution Thomas Edison State University - and examines how the University's history intersects with both the renewed upsurge in interest in $\mathrm{CBE}$ as well as the changing dynamic of what constitutes a robust and successful CBE program. It will also illustrate the achievements and obstacles the core CBE team encountered through their journey to realize a modern direct assessment program.
\end{abstract}

KEY WORDS: competency-based education, new models, adult education, Thomas Edison State University

\section{INTRODUCTION}

The late 1960's and early 1970's were a time of dramatic change and upheaval for higher education in the United States. With the passage of the Higher Education Act of 1965, as well as the baby boom and the civil rights movement, college enrollments swelled throughout the country. Despite this increase in the attendance, there was a growing concern that students - especially non-traditional students - were not being adequately served. Numerous reports, generated by the U.S. Department of Health, Education, and Welfare (HEW) between 1968 and 1972, called for reforms to address issues related to access and affordability. In response, the Fund for the Improvement of Postsecondary Education (FIPSE) was created by Congress in 1972 and empowered to provide funding for unique institutions to try new modalities that would better serve non-traditional populations (Smith et al., 2002). 
Thomas Edison State College (TESC) was one of a handful of schools founded in the early 1970's and assisted by FIPSE with the goal of providing access to higher education for adult students. SUNY Empire State College, Regents College (now Excelsior), and Charter Oak State College all have similar origins, and emerged from the same college access and completion agenda. What made these schools unique was their focus on student outcomes, rather than seat time, and their willingness to accept authentic demonstrations of competencies as a proxy for learning.

Fast forward 45 years, and higher education in the United States is at a similar point of uncertainty. While enrollments surged throughout the Great Recession, so did the cost of tuition, causing many to question whether the increasing cost of a college degree reflected its value. Even the successful completion of a college degree no longer offers the same opportunities in the workforce. According to a 2016 study done by the Federal Reserve Bank of New York, as many as $45 \%$ of recent college graduates are employed in a role that does not require a college degree (Abel and Deitz, 2016). Once again students, parents, and policymakers wonder if students are being adequately served by the existing institutions. And in response to the public's outcry for accountability, educators are once again turning towards a model that values outcomes and authentic demonstrations $-a$ model known as competency-based education (CBE).

As Competency-Based Education has come back into style among educators, many authors point to the FIPSE-funded college-completion schools from the 1970s as the first wave of innovators (Thackaberry, 2016). While the methods and tools of measuring college-level learning may have grown in sophistication since then, the core principles remain the same. It does not matter where a student learned something, as long as they can demonstrate it. Seemingly then, it comes as no surprise that all of these early innovators have been experimenting with the more modern version of CBE. Charter Oak State College, Excelsior College, and Thomas Edison State University have all publicly announced that they are developing programs, and are all members of the Lumina-funded Competency-Based Education Network, aimed at developing common standards and design principles for modern CBE.

None of these schools, however, have had the same success as new entrants in the market. Some have released so-called "course-based" competency-based education programs which tie assessments within courses to competencies. However, this model offers few of the advantages that are common of these more modern CBE programs, such as allowing students to advance at their own pace or to earn a credential that does not translate neatly to traditional credit hours. None of these early innovators have yet launched an approved direct assessment program. Meanwhile, schools like Southern New Hampshire University with its College for America (CfA), University of Wisconsin - 
Extension, and Capella University have developed accredited programs that have attracted thousands of students in a few short years (CFA Staff, 2015; Mason, 2016). Why is it then that these early innovators, with their distinctive experience in this model of instruction and assessment, have failed to keep pace? This article will look at the history of a single institution - Thomas Edison State University - to provide insight into the challenges that these legacy institutions face.

\section{COMPETENCY-BASED EDUCATION AT THOMAS EDISON STATE COLLEGE}

Founded the same year as the FIPSE, Thomas Edison State College (TESC) was an institution borne out of the access agenda in Washington, and Malcolm Knowles' theory of andragogy. Situated on the Princeton University campus, TESC was originally comprised of a single pre-war building, and the programs were designed specifically for self-directed adult learners who possessed college-level experience. According to its first course catalog, the college was "established in recognition of the fact that there are many ways to gain knowledge. As a result, it will carry out evaluations of college-level learning, no matter how this learning was acquired - through experience, self-study, college courses taken long ago, educational programs offered by industry, the military or labor unions, and the like" (Thomas A. Edison College, 1973). In short, students could transfer in credits from another institution, participate in the College's credit-by-exam program, or petition the institution to perform what they called a "Special Assessment." Special Assessments are described as "oral, written, and performance examinations or the evaluation of portfolios of artistic, literary, or musical accomplishments" (Thomas A. Edison College, 1973). This methodology was a sharp departure from the traditional 'sage on the stage' academic mindset that had characterized higher education up to this point. It also provided new opportunities for students equipped with relevant life experience to secure an affordable and meaningful credential. In subsequent publications, TESC would refer to this method of evaluation as "competency-based."

Over the next three years, the institution grew to over 3,000 students and began to expand and formalize its offerings. The special assessment was transformed into the portfolio assessment and given more consistent requirements. Students were asked to collect evidence of their mastery, and then to write a short narrative placing that evidence in a biographical and academic context. Meanwhile, the institution added new degree programs and encouraged students to attend other colleges to earn credit towards their degree requirements. In essence, TESC was more of an education aggregator than a formal institution of learning. Over the next decade, however, the College's identity began to change with the introduction of telelearning. 
In 1982, the College began exploring the potential to use (at the time) state-of-the-art technology to provide courses to students. Computer assisted instruction, telecourses, telelearning, teleconferencing, audio courses, satellite delivered instruction, and other learning opportunities were becoming broadly available. College staff recognized that its students - adult distance learners - needed access to these learning opportunities, advice on how to select among them, and support in using them. Significant resources were allocated to developing an institutional capacity to create and administer courses via VHS, public television, and cable networks. By 1998, TESC prided itself as a leader in the field of distance education with over 100 courses available and an inventory of over 9,000 tapes (Seaton, 2011).

While building out their telecourse capacity, TESC began to innovate with other educational technologies. In 1984, FIPSE returned to provide the funding to develop the college's first online instructional capabilities. Christened "Guided Study," this program allowed faculty mentors to engage with the students over email to help facilitate their progress through the telecourses. With the aid of a \$1.8 million Challenge Grant awarded by the N.J. Board of Higher Education in 1986 under the Kean administration, Guided Study quickly evolved into the CALL Network's Simulated Classroom, the institution's first truly online education experience (Maehl, 1999; N.J. State Dept. of Higher Ed., 1987). Students could register and pay for courses, interact with course materials, and contact their faculty mentor, all through an online interface (Seaton, 2011).

Online and telecourses proved to be tremendously popular with students, and as such, resources were increasingly devoted to growing the institutional capacity necessary to provide them. Meanwhile, prior learning assessment changed from the primary offering of the institution, to just one of a suite of services provided to enrolled students. In 2010, the department responsible for internal and external academic offerings - Distance and Independent Adult Learning (DIAL) - was reorganized. The centralized instructional design and learning management system support responsibilities were passed to the newly created Center for Learning and Technology. Meanwhile, prior learning assessment (including portfolio, credit-by-exam, and the College's Academic Program Review office) became the charge of the Center for the Assessment of Learning. This division exemplified the growing conflict between the original mission of the institution and the growth of its most profitable innovation.

Even as TESC was aggressively expanding its course catalog, the nationwide competition for students was increasing dramatically. As online learning entered the mainstream, between 2000-2010 the number of US students enrolled in at least one online course had risen by an incredible $380 \%$, and the total had reached over 6 million students (Allen and Seaman, 2013). Moreover, TESC's specific subset of the higher education market - adult 
students - was increasingly targeted by other providers. Online for-profit universities saw their enrollments swell into the hundreds of thousands through direct marketing campaigns to employers and the armed forces (Davidson, 2015). Despite this, TESC's enrollments continued to rise throughout the 2000's, reaching 20,000 for the first time in 2012 (Pruitt, 2012). Much of this rise can be attributed to increasing active duty military and veteran students who had access to the Post-9/11 GI Bill educational assistance, as well as the massive number of adults who pursued degrees in the wake of the Great Recession (U.S.C. §§3327, 2016).

Despite its success, TESC felt that in such a competitive environment it needed to continue to evolve. Further, there was a growing number of issues with the College's current model including: the rising cost of textbooks and other educational resources, the growing perception of a student skills gap, and the question of how to credential students who had vast knowledge and skills which did not fit squarely into three credit increments (Singer, 2012). As a nexus for assessing and credentialing workplace and non-credit learning, the Center for the Assessment of Learning was slowly converted into a hub for testing out new trends in higher education that aimed to solve some of these issues. In late 2012 , the head of the center successfully lobbied internally for resources to explore the utility of open educational resources (OER), as well as the feasibility of developing a competency-based education program (Thomas A. Edison State College, 2012). Over the next 18 months, the CBE team developed a unique model for modern competency-based education which leveraged the institution's vast experience in assessment, and built upon the themes and goals of its founding.

\section{A NEW MODEL EMERGES}

The road to a competency-based education model was not an easy one. Once the Center for the Assessment of Learning had been granted funding to explore the possibility of building a CBE program, they formed an exploratory committee. The committee, which was comprised of representatives from all corners of the institution, reviewed emerging CBE models such as those of Northern Arizona University, Southern New Hampshire University, Capella University, and Western Governor's University. However, outside of these schools, few institutions had successfully launched a CBE program, and many of those that had shown signs of early success were heavily subsidized by grants. As a result, there was a noticeable dearth of efficacy research that could help support investment in such a large undertaking.

Technology was another area which presented serious obstacles to progress. As of January 2013, TESC had transitioned to using Moodle as the learning management system (LMS) for their traditional online courses (Thomas A. Edison State College, 
2013a). Unfortunately, Moodle's functionality did not enable students to enroll in individualized, self-paced modules, and also lacked means to support the robust coaching that is at the heart of an effective CBE program (Desrochers and Staislof, 2016; Heles, 2014). For TESC, however, replacing Moodle was not an option. Not only did the institution lack the resource capacity to design a technology solution in-house, but they also did not have the funding to capitalize the creation a third-party design. Additionally, after a recent time-consuming and costly conversion from Blackboard to Moodle, there was little appetite for conversations around a new LMS.

Despite the consensus from the initial exploratory committee that there were numerous advantages explicit in the design of a CBE program (student-focused program, which emphasized aggressive faculty coaching, rigorous and transparent outcomes and assessments, and technologically sophisticated design), the committee felt the field needed more time to develop before TESC made any concrete investments in a CBE program. The committee did, however, produce a whitepaper which detailed a number of elements that they felt were critical to the development of a program that leveraged the College's history and expertise. Among them were:

1. Clearly defined, discrete assessments

2. Transparent competency statements that combined workforce application with liberal studies

3. A vigorous diagnostic intake process that leveraged the school's prior learning assessment expertise

4. Commitment to OER (Thomas Edison State College, 2013b)

The committee submitted its report in December of 2013, recommending close observation of the CBE field, but no overt action. However, in an attempt to maintain the momentum and optimism towards this kind of modern CBE, a few committee members turned their focus towards legitimizing the individual features of the program. The first challenge they needed to overcome was to develop a competency framework for a degree program.

As mentioned previously, there were few existing CBE models that could be evaluated or leveraged. Further, regulatory guidance was almost non-existent, and where it did exist, was contradictory and confusing. As such, TESC had to rely on its existing curriculum and requirements to serve as the foundation for its CBE model. The CBE team selected two degree programs that would serve as the pilot sandboxes for innovation: the Masters of Business Administration (MBA), and the Associates of Arts in Liberal Studies (AALS). These selections would allow the team to experiment with both undergraduate and a 
graduate degrees. Further, by building out the AALS, they would have an opportunity to tackle the institution's general education requirements. Once competencies were created that could satisfy the general education requirements, they could be leveraged to form the basis for future development of a Bachelor's degree. Based on the recommendations from the original exploratory committee's white paper, the CBE team decided to design both degrees as direct assessment programs, rather than course-based competency programs. While this choice led to an increase in the complexity of the design process, the team felt that a direct assessment program provided significantly more value to students in terms of transparency of the credential, cost effectiveness, and speed to degree.

Each degree was tackled independently by a committee of faculty subject matter experts, supported by the CBE team. The AALS committee started by reviewing the institutional degree requirements for the established program, as well as two field-facing frameworks designed to provide reference points for degree level proficiencies: the AAC\&U Valid Assessment of Learning in Undergraduate Education (VALUE) rubrics, and the Lumina Foundation's Degree Qualifications Profile (DQP) (Adelman et al., 2014; Association of American Colleges \& Universities, 2009). This committee quickly realized that the dimensions dictated by the DQP were not quite inclusive enough to be used a guide. For example, in the Ethical Reasoning section, the DQP asks students to identify and analyze ethical issues in politics, economics, health care, technology, etc. However, the DQP lacked any discussion of ethical decision making or self-reflective ethics. Meanwhile, the committee found the VALUE rubrics to be more aligned with the task of determining the dimensions for degree level assessment. The rubric's core expectations provided the committee with a useful mental framework, and ultimately their impact is clearly visible in the finalized competency map.

After months of collaboration, the AALS committee settled on a three-tiered hierarchy of Competency Groups, Domains, and Statements. Competency Groups were designed as a collection of domains scaffolded with increasing complexity and rigor. Group 1 focused on the practical and intellectual skills that a student needs to succeed in a college environment and included domains such as written and oral communication, information literacy, quantitative literacy, etc. Group 2 encourages students to take those skills and apply them in a variety of subject-based contexts. This group featured domains such as Intercultural Knowledge, Ethical Reasoning, and Global Learning. Finally, Group 3 focuses on transferability and metacognition, asking students to reflect on their education and use their skill and subject abilities in new ways. Competency Domains embodied the overarching themes from the degree program. It was here that some of the core expectations from the VALUE rubrics were introduced. 
Competency Domains framed institutional outcomes in ways that would be recognizable to current and future stakeholders (i.e. graduate school, employers, etc.). Finally, Competency Statements detailed discrete skills and abilities in which students would demonstrate their mastery. To develop these statements, the committee reviewed all of the courses that satisfied the various degree requirements in the AALS, and selected common themes (i.e. in all courses that speak to the institution's information literacy requirement, which skills and activities are repeated.) The number of competency statements per domain varied based on the complexity of the domain content. This smallest tier would be the level at which students in the direct assessment program would be credentialed.

Meanwhile the MBA committee took a slightly different approach. While they were consistent with the design of a three-tiered framework, rather than constructing the groups based upon complexity, they divided the competency domains between required and elective. Simply, the competency domains in the required group reflected the core expectations of the degree program, and served to provide students with a foundation in graduate work. Through the competency domains in the elective group, students could select their unique specialization within the MBA programt. The committees differed with how they developed competency statements as well. Whereas the AALS committee created new statements based on repeating themes, the MBA committee used the MBA course objectives as their underpinning. Much of their work entailed modifying the existing objectives with an eye towards assessment and workforce application.

These competency frameworks were well received by both the School of Business and Management and the School of Arts and Sciences leadership. This work, and the lengthy approval process that each framework went through with their respective curriculum committee, kept competency-based education in the front of mind for many at TESC. However, even after the framework's approval, there was no signal that there would be a firm commitment from institutional leadership for the development of a fully-fledged direct assessment program. In the background of the CBE experimentation, TESC enrollment had declined for the first time since the 1990s, and the number of students registering for portfolio assessments was close to an all-time low (Thomas Edison State College, 2014). The College began considering a variety of cost-cutting measures, and as such, investments in new methods were not a popular topic. However, having confidence in the intrinsic value of $\mathrm{CBE}$, and in an effort to revitalize the sagging portfolio numbers, the CBE team pressed forward and continued their experimentation with another key element of the proposed program - the diagnostic intake interview. They believed that by combining elements of our existing portfolio assessment processes with a more robust faculty 
coaching model, they could produce an effective diagnostic that would set students up for success.

Over the past four decades, TESC model for portfolio assessment has gone through several alterations. However, the foundational aspects of the process remain unchanged. Traditionally, if a student is interested in earning credit through a portfolio assessment, they start out by searching through the TESC portfolio database for the course or courses that best reflects their experience. Once the selection had been approved by a TESC assessment expert, the student begins compiling evidence that their experience had imbued them with college-level credentials that satisfy the relevant learning outcomes. Evidence can take the form of work products, essays, letters of recommendation, certifications, etc. Along with evidence, the student writes a narrative essay that reflects on their experience and connected it to the course outcomes. Upon completion, the portfolio is evaluated by a faculty mentor (Hoffmann, 2014).

Meanwhile, the advising services provided to TESC students principally included helping select which courses would satisfy specific degree requirements, confirming withdrawal deadlines, and other specific college guidelines. Psychologist Dr. B. B. Crookston described this type of authority-based question and answer advising as prescriptive advising. He stated, "Advisors who use a prescriptive advising approach do not take total individual development into consideration. Instead they focus on expressing institutional authority" (Crookston, 1972). This method is contrasted against developmental advising, which takes into account human growth, cognitive, affective, career, physical, and moral personal goals and objectives (Jordan, 2000). While prescriptive advising is much more cost effective and scalable, the CBE team believed that it was insufficient to support students moving through an already isolating and self-driven competency-based direct assessment experience. Given the fact that few TESC students utilize the existing advising services, they believed that a different approach was required for this subset of students.

The CBE diagnostic intake process would begin after the student had applied, but before they had enrolled in a degree program. If they chose to take the CBE route, they would be directed to the competency degree map, which would list all of the competencies, associated assessments, and rubrics for a specific degree. Next, much like traditional portfolio students, they would collect evidence and construct a narrative for the evidence. In this model however, they complete this process with competencies in mind, rather than course objectives, and in the context of an entire degree program, rather than individual courses. Once the student submits a diagnostic portfolio, it would be reviewed by a team consisting of an assessment specialist and one to three subject matter experts (depending on the scope of the student's experience). During this preliminary evaluation, the 
committee would evaluate students in each competency they chose to challenge, on a four-level rubric (Thomas Edison State College, 2013).

The next step in this process would be to engage in an interview with the student, conducted over the phone, through video conferencing software, or in-person, depending on the preference of the student. During these interviews, the committee would probe further into the student's experience in order to make concrete determinations regarding their level of mastery. Also participating in the interview would be the student's TESC assigned coaching mentor. This subject matter generalist would be paired with a student during this initial interaction, and would become the main point of contact for the student's entire academic career. Through this role, the CBE team hoped to add an element of developmental advising to this program. Once the diagnostic intake interview was completed, the coaching mentor would schedule their first of many regular check in calls with the student and discuss the results. Together, the student and the coaching mentor would create a plan of action, and discuss the next steps for enrolling in a degree program and registering for competency modules.

Working together with the School of Business and Management, the CBE team tested this process with a number of pilot MBA students in the late spring of 2014. They focused on a set of competency statements within the MBA degree program that could be traced back to a traditional three credit course. This way, students who volunteered to participate in the pilot would be able to receive credit. The student response was overwhelmingly positive, but the pilot did reveal some potential issues. The first obstacle was related to documentation. All of the students who participated had rich conversations with the evaluation team that uncovered experience and competency far beyond the initial portfolio submission. Unfortunately, aside from the team's notes and the information which was detailed in the rubrics, there was no way to capture this richness. Further, all grading and record keeping was manual. This was not an issue for the purposes of the pilot; however, the team agreed that, where possible, the introduction of technology and automation was necessary for effective scalability.

On the back of these initial efforts, TESC's leadership approved additional exploration. They commissioned a detailed project plan, cost and enrollment projections, and began discussions with Middle State Commission on Higher Education (MSCHE). The CBE team estimated that the overall costs for developing a direct assessment program would cost in the low seven figures spread across three years. By the fourth year, the program would become cash positive, and it would break even by year six. However, given the budgetary constraints of the institution, the CBE team was granted a budget in the low six figures to continue to pursue their experimentation, and was encouraged to seek additional funding from the College's independent, charitable fundraising foundation and alumni association. 


\section{IMPLEMENTATION CHALLENGES}

With the budget in hand, the CBE team began to move forward on several fronts. The main priorities were to develop a curriculum and to select a technology solution that could be used to both deliver the curriculum as well as support the robust coaching model they envisioned. Without the capacity to recruit an internal instructional design team, they needed to look elsewhere for curricular support. Further complicating matters was the CBE team's steadfast commitment to using open education resources (OER) throughout the curriculum. They felt that there was a natural synergy between the modularity of a CBE program and flexibility provided by OER. By using OER, students would not be required to purchase an entire textbook to use the relevant chapter(s) for a given module. Moreover, the CBE team at Thomas Edison State University (TESU) † was keen to start a larger conversation within the CBE community around questions of standardization. By providing other schools with a universal CBE framework that was open and customizable, the TESU team believed they could create a foundation for that conversation. However, this meant that partnering with commercial publishers to provide competency module content would not be an option.

Instead they turned to the non-profit Saylor Academy for assistance. Since 2010, Saylor Academy had developed an extensive library of over 300 open courses. TESU and Saylor had collaborated closely on a number of projects, including TESU Open Course Option Associates of Science in Business Administration degree. As such, the CBE team at TESU had great confidence in Saylor's open and self-paced course design abilities, and the team began to build out curriculum for the Associates of Arts in Liberal Studies. Of the two competency degree maps that the CBE team had developed, the AALS was the more popular of the two degree programs and there was a larger library of potential OER to draw from at an undergraduate level. The team hoped that an early success with the AALS would open up more funding for future development.

The biggest concern with choosing Saylor was the question of whether their course design abilities could be applied to creating competency modules. Within any traditional credit course, the goal is to expose students to a particular topic area. Through that experience, it's possible a student may acquire some skills, but the primary goal is knowledge acquisition. Competency modules, as conceived by TESU, were discrete educational experiences centered on helping students perform a particular skill or ability. Therefore, a unique orientation was required. The CBE team worked with Saylor and their subject matter experts to develop a robust system of oversight to ensure that the modules reflected this orientation. 
Selecting a technology partner was also a challenge. While the education technology market had recognized the growing need for tools that supported CBE programs, the lack of a coherent set of standards or requirements from the CBE field made it difficult for them to formulate a response. Many defaulted to offering course-based learning management platforms with a veneer of $\mathrm{CBE}$, but nothing that would effectively support a direct assessment program. Curriculum was still focused around course shells, made up of subunits with an overarching set of competencies, viz. learning outcomes. For instance, an institution might be able to define which competencies would be measured within an assessment (similar to how traditional LMS products track learning outcomes), but there would be no way to use completion of an individual competency as a credential for advancement outside the context of the course shell. Even in conversations with vendors, some would accidentally say "courses" when they were referring to their CBE substitutes.

After an exhaustive search of the options - which at the time included Flatworld Knowledge, Southern New Hampshire University's spin-off Motivis Learning, LoudCloud's FASTRAK, Educate Online's Total Competency Management, Lumen Learning's Waymaker, Learning Objects' Difference Engine, and Ellucian's Brainstorm - TESU decided to move forward with Brainstorm. Ellucian was still in the early stages of adapting Brainstorm after purchasing the software from Datamark, and offered TESU a spot in their beta "early adopters" program. This program promised a reduced price and extensive training in exchange for feedback and testing. The CBE team hoped that given the technology's immaturity, and their positioning, they would be able to have a strong voice in crafting the outcome and ensure that the finished platform effectively supported their curriculum. Also, given that TESU used Ellucian's Colleague product for their Student Information System (SIS), they hoped there might be seamless integration between the technologies. Finally, the reduced cost accommodated TESU's modest budget.

As work on the curriculum and the LMS continued, the CBE team started to consult with other departments at the institution that would be crucial for a successful implementation. This process was however, not without its challenges. Given the bottom-up origination of the CBE program at TESU, (emerging from continued experimentation within the CAL), there was no clear institutional mandate for its continuation. Non-academic departments, already dealing with a full workload, were unclear as to how much, if any, of their resources should be allocated to working with the CBE team. As such, many of the backend processes involving admissions, the bursar, and the registrar were challenged to advance past the initial draft stages. 


\section{LOOKING FORWARD}

As of June 2017, the future of CBE at TESU is uncertain. Many of the challenges that had been recurring themes throughout the development still have not yet been resolved. With the shutdown of Brainstorm in January, the team is exploring new LMS products. However, over the last few months the CBE technology market has dramatically changed. Learning Objects was acquired by Cengage, and LoudCloud bought by Barnes \& Noble. Flatworld Knowledge sold its online publishing arm, and rebranded itself as a CBE-first company named Sagence. Educate Online (now Meteor Learning) and Lumen Learning have shifted their products to focus more on course-based CBE that would not be appropriate for the TESU model. This contraction limits the potential pathways forward, especially for an institution with a direct assessment model (Hill, 2016, 2017; Straumsheim, 2017).

The regulatory climate is also hazy. Policy experts have been teasing the release of the results of an Office of Inspector General (OIG) investigation into popular CBE destination, Western Governors University, since late 2016. This report could determine that WGU's CBE model failed to satisfy the "regular and substantive interaction" requirement for student-faculty interaction. This condition is one of the main criteria that separates correspondence and telecommunication courses, and determines Title IV financial aid eligibility (Fain, 2016; Poulin and Davis, 2016). This scenario would likely have a significant chilling effect on regional accreditor approval for similarly-designed programs. Further, there is no clear indication that the Department of Education's Experimental Sites Initiative for subscription-based CBE programs will continue through a Trump Administration. Nor are there signs that the experiment, if discontinued, will lead to transformative legislation that would open the door to institutions who want to provide financial aid to modern direct assessment studentst.

In spite of these challenges, the CBE team at TESU continues to move forward. The curriculum development for the AALS degree is slated to be completed in second half of 2017, and discussions have begun with a new technology vendor. The team has also made significant progress towards the submission of a Substantive Change Proposal to the institution's accreditor MSCHE. The creation of this document has catalyzed some of the conversations surrounding back-end processes that just a few months ago had stalled. One further bright spot comes from the institution's independent, charitable fundraising foundation. In recent months, they have succeeded in securing donations that will be used towards a replacement LMS for Brainstorm and additional staff training. However, additional funding will be required to ensure the long-term sustainability of this program.

Thomas Edison State University was founded as an institution which valued what a student knew and could do, rather than where they learned how to do it. This emphasis on 
competencies rather than course time equipped the University to provide a quality education and meaningful credential for a population that did not fit into the traditional higher education model. That mission is still, if not more, relevant to today's students. However, the infrastructure that provided for these students was supported through generous funding from both federal and state entities. Innovation is not cheap, and without the generous support of FIPSE and grants by the N.J. Board of Higher Education, TESU could never have become the technological sophisticated sanctuary for adult students that it is today. Given the atmosphere of shrinking enrollment, declining state and local funding, and increased competition from other institutions, TESU must look to new funding sources and novel approaches in order to maintain its competitive advantage, and continue to provide students with the best possible educational experience.

\section{NOTES:}

$\uparrow$ Potential MBA specializations include: Data Analytics, Marketing, Finance, Human Resource Management, Healthcare Management, and Strategic Management.

$\uparrow$ Gained University status in 2016

$\uparrow$ There is a bill in Congress (unrelated to the ESI), introduced in June 2017, that would allow for a CBE demonstration project, however, it's unclear what the timeline or likelihood of its passage may be. https:/www.congress.gov/bill/115th-congress/house-bill/ 2859.

\section{REFERENCES}

Abel, J.R. and Deitz, R. (Jan. 11, 2016), Working as a Barista After College Is Not as Common as You Might Think, Liberty Street Economics: Federal Reserve Bank of New York. Retrieved March 15, 2017 from http://libertystreeteconomics.newyorkfed.org/2016/ 01/working-as-a-barista-after-college-is-not-as-common-as-you-might-think.html\#.VpPCi_ k4Fph .

Adelman, C., Ewell, P., Gaston, P. and Geary Schneider, C. (2014), The Degree Qualifications Profile, Lumina Foundation. Retrieved March 15, 2017 from http:// degreeprofile.org/read-the-dqp/dqp-cover/.

Advancing Competency-Based Education Act of 2017, H.R.2859. Retrieved March 15, 2017 from https://www.congress.gov/bill/115th-congress/house-bill/2859.

Allen, I.E. and Seaman, J. (2013), Changing Course: Ten Years of Tracking Online Education in the United States, Babson Survey Research Group and Quahog Research Group, LLC. Retrieved March 15, 2017 from https://www.onlinelearningsurvey.com/ reports/changingcourse.pdf.

Association of American Colleges \& Universities VALUE Rubrics (2009). Retrieved March 15, 2017 from https://www.aacu.org/value-rubrics. 
CFA Staff (2015), Survey: Thousands of College for America students earn debt-free degrees, give high marks for career applicability, College for America Blog. Retrieved May 22, 2015 from http://collegeforamerica.org/student-survey-thousands-of-college-foramerica-students-are-earning-debt-free-degrees-give-high-marks-for-career-applicability/.

Crookston, B.B. (1972), A Developmental View of Academic Advising As Teaching, Journal of College Student Personnel, vol. 13, pp. 12-17.

Davidson, J. (2015), How For-Profit Colleges Target Military Veterans (and Your Tax Dollars), Money Magazine. Retrieved March 15, 2017 from http://time.com/money/ collection-post/3573216/veterans-college-for-profit/.

Desrochers, D., Staislof, R. (Oct. 18, 2016), Competency-based Education: A Study of Four New Models and Their Implications for Bending the Higher Education Cost Curve. Retrieved April 1, 2017 from http://rpkgroup.com/wp-content/uploads/2016/10/rpkgroup_ cbe_business_model_report_20161018.pdf.

Election to Receive Educational Assistance, 2008, 38 U.S.C. $§ \S 3327$ (2016). Retrieved March 15, 2017 from https://www.law.cornell.edu/uscode/text/38/part-III/chapter-33.

Fain, P. (Jan. 15, 2016), “The Faculty Role Online, Scrutinized, Inside Higher Ed. Retrieved April 20, 2017 from https://www.insidehighered.com/news/2016/01/15/ education-departments-inspector-generals-high-stakes-audit-western-governors-u.

Heles, T. (Oct. 7, 2014), "Motivis Learning spins out with \$7m." Global university Venturing. Retrieved March 1, 2017 from http://www.globaluniversityventuring.com/ article.php/3985/motivis-learning-spins-out-with-7m.

Hill, P. (March 9, 2016), "Barnes \& Noble Education Buys LMS Provider LoudCloud Systems for \$17.9 Million", Inside Higher Ed. Retrieved April 30, 2017 from http:// mfeldstein.com/barnes-noble-education-buys-Ims-provider-loudcloud-systems/.

Hill, P. (Feb. 14, 2017), "Ellucian Stops Support for Brainstorm, its CBE platform." e-Literate. Retrieved April 10, 2017 from http://mfeldstein.com/ellucian-stops-supportbrainstorm-cbe-platform/.

Hoffmann, T. (2014), PLA-200: Introduction to Portfolio Development, Thomas Edison State University. Retrieved April 30, 2017 from https://sites.google.com/a/courses.tesc. edu/pla-200-public/.

Internal Enrollment Report, Thomas A. Edison State College, 2014.

Internal Grant Proposal, Thomas A. Edison State College, 2012.

Jordan, P. (2000), Advising College Students in the 21st Century. NACADA Journal, 20(2), pp. $21-30$. 
Maehl, W. (1999), Lifelong Learning at Its Best: Innovative Practices in Adult Credit Programs, Hoboken, N.J.: John Wiley \& Sons, Inc.

Mason, K.C. (Sept. 2, 2016), UW Flexible Option Program Sees 800 Students, 26 Graduates 2.5 Years After Launch, Wisconsin Public Radio. Retrieved April 30, 2017 from http://www.wpr.org/uw-flexible-option-program-sees-800-students-26-graduates-2-5-yearsafter-launch.

New Jersey State Dept. of Higher Education (1987), Annual Report on Higher Education in New Jersey, 1986-87. Retrieved March 1, 2017 from https://archive.org/stream/ ERIC_ED304982/ERIC_ED304982_djvu.txt.

Pruitt, G.A. (2012), Report of the President to the Members of the Board of Trustees, Thomas A. Edison State College. Retrieved May 22, 2015 from https://www.tesu.edu/ about/documents/Presidents_Annual_Report.pdf.

Poulin, R. and Davis, V. (Sept. 30, 2016), "Interpreting What is Required for 'Regular and Substantive Interaction"', WICHE Cooperative for Educational Technologies (WCET). Retrieved April 1, 2017 from https://wcetfrontiers.org/2016/09/30/interpreting-regular-andsubstantive-interaction/.

Thomas A. Edison State College (2013a), Report of the President to the Members of the Board of Trustees.

Seaton, W.J. (2011), The Computer Assisted Lifelong Learning (Call) Network of Thomas Edison State College, DOESNEWS 8(1), pp. 1-11. Retrieved May 22, 2015 from http:// learningdesign.psu.edu/assets/uploads/deos/deosnews8_1.pdf.

Singer, Marc (2012), Why Thomas Edison State College, and New Jersey, Need Competency-Based Education (unpublished internal memo). Thomas Edison State College.

Smith, V.B., Immerwahr, J., Bunting, C.I., DeMeester, L., Garth, R., Hendrix, R., Justice, D.O., Lewis, R., McGonagill, G., Stoel, C. (2002), Fund for the Improvement of Postsecondary

Education: The Early Years, The National Center for Public Policy and Higher Education. Retrieved March 1, 2017 from http://www.highereducation.org/reports/fipse/FIPSE.pdf.

Straumsheim, C. (March 20, 2017), "Finding a Niche in a Niche Market", Inside Higher Ed. Retrieved March 1, 2017 from https://www.insidehighered.com/news/2017/03/20/ competency-based-education-remains-niche-market-software-vendors.

Thackaberry, A.S. (2016), A CBE Overview: The Recent History of CBE, The EvoLLLution. Retrieved March 1, 2017 from http://evolllution.com/programming/applied-and-experientiallearning/a-cbe-overview-the-recent-history-of-cbe/. 
Thomas A. Edison College (1973), The External Degree Program of New Jersey, 19731974, Trenton, NJ: Thomas A. Edison College, pp. 5-11.

Thomas Edison State College (2013b), A Continued Tradition: Competency-Based Education at Thomas Edison State College (internal white paper), Trenton, New Jersey. 